\title{
Comparison of Predicted and Adult Heights in Short Boys: Effect of Androgen Therapy
}

\author{
SANDRA L. BLETHEN, ${ }^{(12)}$ SHARON GAINES, AND VIRGINIA WELDON \\ The Edward Mallinckrodt Department of Pediatrics, Washington University School of Medicine and The \\ Division of Endocrinology and Metabolism, St. Louis Children's Hospital, St. Louis, Missouri, USA
}

\section{Summary}

We evaluated the accuracy of height predictions based on the tables of Bayley and Pinneau (2) in 43 boys with short stature. Sixteen boys were treated with androgens and 27 received no treatment. In 17 boys whose bone ages were within normal limits, and who received no treatment, the mean $\pm S E$ predicted height of $164.9 \pm 1.5 \mathrm{~cm}$ was not significantly different from the mean adult height $(166.5 \pm 1.5 \mathrm{~cm})$. The predicted height exceeded the actual adult height by more than $5.1 \mathrm{~cm}$ in only one instance [5.1 cm is the degree of accuracy reported by Bayley and Pinneau (2)]. In 10 boys, whose bone ages were severely delayed (more than $2 \mathrm{SD}$ below their chronologic age) and also were not treated, predicted height overestimated adult height by more than $5.1 \mathrm{~cm}$ in five of them. This difference was statistically significant $(P<$ 0.05).

In five boys with normal bone ages, androgen therapy had no significant effect on either predicted height $(168.1 \pm 4.1$ before, $166.8 \pm 4.4 \mathrm{~cm}$ after) or actual adult height $(166.5 \pm 4.1 \mathrm{~cm})$. The 11 boys with severely delayed bone ages had a significant increase in predicted height during androgen therapy (165.4 \pm 1.5 to $169.8 \pm 1.7 \mathrm{~cm}, P<0.01)$, but actual adult height $(162.4$ $\pm 2.4 \mathrm{~cm}$ ) was not significantly greater than pretreatment predicted height. Further, the number of boys whose predicted height exceeded their adult height by $5.1 \mathrm{~cm}$ was not significantly different in treated $(4 / 11)$ or untreated $(5 / 10)$ boys.

The Bayley-Pinneau method of predicting adult height markedly overestimates adult height in about one-half of boys who have a bone age delay of more than $2 \mathrm{SD}$. Short-term therapy with androgens does not alter this outcome.

In evaluating the effectiveness of therapies which might alter growth, two factors are important. The first, the effect of the treatment on growth velocity, can be determined in a relatively straightforward manner provided the child is observed for sufficiently long periods of time with and without the intervention to be tested. The second and more important factor, increased actual adult height, is more difficult to evaluate directly because it requires follow-up until final height is attained. Many investigators have tried to circumvent this problem by comparing changes in height age to those of bone age during treatment, or by calculating predicted heights.

The most commonly used method of predicting adult height was developed by Bayley and Pinneau from a study of a 136 normal children (2). This method uses the skeletal atlas of Greulich and Pyle (5). Longitudinal studies of normal children have verified the accuracy of this method. In most cases, adult height is within $5.1 \mathrm{~cm}$ (2 inches) of predicted height $(1,10)$. Even in boys who were moderately short (heights between the third and fifth percentiles for age), this method was accurate (6); however, the reliability of predicted height estimates in short children, especially those with severe short stature (height less than the third percentile for chronologic age) is less certain. Further, the question as to whether an increase in predicted height with therapy is associated with an adult height greater than that predicted before therapy has not been answered. In this paper, we report a retrospective study including final adult heights of 43 men who were evaluated as boys for short stature with or without evidence of delayed puberty. In addition, we report the effect of androgen therapy on predicted height and actual adult height in 16 of the 43 who received treatment.

\section{MATERIALS AND METHODS}

The charts of all boys with short stature (height less than the fifth percentile) seen in the pediatric endocrine clinic of St. Louis Children's Hospital from July 1968 to December 1981 were reviewed. Patients with evidence of growth hormone deficiency, other organic causes of short stature or evidence for a syndrome associated with short stature were excluded from this study. One hundred and four men, born before 1964, were identified as being suitable for study and attempts were made to contact them. We succeeded in contacting 43 . Heights were self-reported by 32 , obtained from physicians' records in three, and measured by the authors in eight cases. All individuals reported that they had had no height increase for at least $2 \mathrm{yr} ; 41$ were over $20 \mathrm{yr}$ of age. The two 19-yr-old men had not had delayed bone ages when seen in clinic and reported no increase in height for the previous 2 yr. Bone ages had been determined by two highly skilled pediatric radiologists at the Mallinckrodt Institute of Radiology. The method of Greulich and Pyle was used (5). Predicted heights were calculated based on the height at the time of bone age determination using the method of Bayley and Pinneau (2). When there was a marked discrepancy between ossification centers, the bone age based on the phalanges was used in predicting the adult height. In 22 patients (five treated, 17 not treated), bone age was within 2 SD of chronologic age. In 21 (11 treated, 10 not treated), the bone age delay was severe (bone age more than 2 SD below chronologic age). A height prediction was considered to be satisfactory if the adult height was within 5.1 $\mathrm{cm}$ of the predicted height. This is the degree of accuracy reported by Bayley and Pinneau (2).

In the 16 individuals who were treated with androgens, pretreatment predicted height was calculated on the basis of the bone age obtained at the time androgen therapy was initiated, and treated predicted height was calculated on the basis of bone age at the time androgen therapy was discontinued. The duration of androgen therapy varied from 4 to 18 mo (mean $8.3 \pm 0.9$ mo). Fourteen individuals were treated with stanozolol (Winstrol), one with oxandrolone, and one with testosterone enanthate. Therapy was discontinued when the boy showed evidence of spontaneous progression of puberty. 
BLETHEN $E T A L$.

Table 1. Adult height outcome in boys with short stature

\begin{tabular}{|c|c|c|c|c|c|c|}
\hline \multirow[b]{2}{*}{ Treatment } & \multicolumn{3}{|c|}{ Age (yr) } & \multicolumn{3}{|c|}{ Height $(\mathrm{cm})$} \\
\hline & Chronologic & Height & Bone & Adult & Predicted* & Predicted A $\dagger$ \\
\hline \multicolumn{7}{|l|}{ None } \\
\hline $\begin{array}{l}\text { Bone age not } \\
\text { delayed (17) }\end{array}$ & $13.1 \pm 0.4$ & $10.6 \pm 0.4$ & $12.2 \pm 0.4$ & $166.5 \pm 1.5$ & $164.9 \pm 1.5$ & $\cdots$ \\
\hline $\begin{array}{l}\text { Delayed bone } \\
\text { age (10) }\end{array}$ & $12.6 \pm 0.5$ & $9.5 \pm 0.6$ & $9.6 \pm 0.6$ & $166.3 \pm 1.9$ & $169.3 \pm 2.4$ & $\cdots$ \\
\hline \multicolumn{7}{|l|}{ Androgen } \\
\hline $\begin{array}{c}\text { Bone age not } \\
\text { delayed (5) }\end{array}$ & $14.6 \pm 1.1$ & $11.6 \pm 1.3$ & $13.2 \pm 0.8$ & $166.5 \pm 4.1$ & $166.8 \pm 4.4$ & $168.1 \pm 3.8$ \\
\hline $\begin{array}{l}\text { Delayed bone } \\
\text { age (11) }\end{array}$ & $14.3 \pm 0.6$ & $9.8 \pm 0.4$ & $10.6 \pm 0.5$ & $162.4 \pm 2.4$ & $165.4 \pm 1.5$ & $169.8 \pm 1.7 \ddagger$ \\
\hline
\end{tabular}

* Predicted height just before androgen therapy in those who were so treated.

$\dagger$ Predicted height at the cessation of androgen therapy.

$\$ P<0.01$ compared with both predicted height before therapy and actual adult height.

Table 2. Accuracy of height predictions*

\begin{tabular}{ccc}
\hline Patient & $\begin{array}{c}\text { Satisfactory } \\
\text { adult height }\end{array}$ & $\begin{array}{c}\text { Adult height } \\
\text { overestimated }\end{array}$ \\
\hline No treatment & & \\
No bone age delay & 16 & 1 \\
Delayed bone age & 5 & $5 \dagger$ \\
Androgen treated & & \\
No bone age delay & 4 & 1 \\
Delayed bone age & 7 & 4 \\
\hline
\end{tabular}

*A delayed bone age was one that was more than 2 SD below the mean for chronologic age. A satisfactory adult height was one no more than 5.1 less than the predicted height.

$\dagger P<0.05 v s$ no bone age delay.

The data are reported as mean \pm SEM. Because the individuals studied represented an extreme of the normal population, nonparametric statistics (Fisher's exact, Wilcoxon's signed rank and rank sum tests) were used to determine the signifiance of differences between groups (9).

\section{RESULTS}

The characteristics of the patients studied are shown in Table 1. The groups did not differ significantly in chronologic age or height age. For each group, however, bone age and height age were significantly less than chronologic age $(P<0.01$, Wilcoxon's signed rank). As might be expected, a greater fraction of the boys who received androgen therapy were less than the third percentile in height for chronologic age (14 of 16 versus 19 of 27), but this difference was not statistically significant $(P>0.4$ Fisher's exact test).

In the group of boys who received no treatment, mean predicted height was not significantly different from mean adult height whether or not there was severe bone age delay. But, there were more unsatisfactory predictions in boys with severely delayed bone ages (Table 2). In five of 10 of these boys, predicted height exceeded adult height by more than $5.1 \mathrm{~cm}$ (mean error, $9.0 \pm 1.3 \mathrm{~cm}$ ). Only one boy whose bone age was within normal limits for his age had such a marked overestimation of adult height (error $6.3 \mathrm{~cm})$. This difference is statistically significant $(P$ $<0.05$, Fisher's exact). There was no significant correlation between chronologic age at the time a height prediction was made and the degree to which adult height differed from predicted height $(r=0.17)$.

Androgen therapy was undertaken in 16 boys, (five with normal bone ages and 11 with delayed bone ages). In boys who did not have severely delayed bone ages, androgen therapy had no statistically significant effect on either predicted height or actual adult height. Among the boys with delayed bone ages, androgen therapy resulted in a significant increase in predicted height. This increase in predicted height, however, was not followed by a final adult height greater than the pretreatment predicted height. Although all boys with severely delayed bone ages had an increased predicted height while on androgen therapy, only three reached an adult height greater than the pretreatment predicted height. The average discrepancy between pretreatment predicted height and actual adult height was not significantly different from that observed in boys with delayed bone ages who were not treated (Table 1). Neither the total number of men whose adult height differed from pretreatment predicted height by more than $5.1 \mathrm{~cm}$, nor the number of adult height overestimates in the treated group was significantly different from that observed in the group which did not receive androgen therapy (Table 2). There was no significant correlation between duration of therapy and outcome $(r=-0.19)$.

In eight boys who were treated with androgens, bone age determinations were obtained (6-24 mo) after androgen therapy had been discontinued. In two boys, there appeared to have been an undue acceleration of bone age relative to chronologic age after discontinuation of androgens (18 mo versus $12 \mathrm{mo}$ in one and 12 mo versus 6 mo in the second). Both had had severe bone age delay before treatment. The final height of the first was $10 \mathrm{~cm}$ below his predicted height, that of the second was $4.2 \mathrm{~cm}$ less than his pretreatment predicted height. This degree of bone age acceleration was not noted in the other boys and predicted height continued to exceed pretreatment predicted height for up to 2 yr after cessation of treatment.

\section{DISCUSSION}

In reporting height predictions to a child and his family, most clinicians give only conservative estimates, in keeping with the $5.1 \mathrm{~cm}$ degree of accuracy reported by Bayley and Pinneau. Studies on normal children and those with mild growth retardation have indicated that $95 \%$ of adult heights will fall within this range of height estimates $(1,2,6)$. Our study indicates that even in boys with severe short stature, such estimates are accurate provided the child does not have a bone age more than 2 SD below chronologic age at the time the height prediction is made.

Although it has been suspected that Bayley-Pinneau height predictions were less accurate in children with marked bone age delays (6), the magnitude of the error and the fact that adult height is markedly overestimated in one-half of these boys may not have been appreciated because the most commonly recommended treatment for a child with short stature and a delayed bone age is reassurance $(4,6,8)$. Our results suggest that reassurance may not be an appropriate way to deal with these boys.

We found that a significant increase in predicted height with androgen therapy occurred only in boys with severely delayed bone ages. A number of authors $(5,7,8)$, have reported that androgen therapy results in an increase in predicted height, but they have not commented on the difference in results between boys who have severely delayed bone ages and those who do not. 
Most authors who have treated short children with androgens have refrained from claiming that an increase in predicted height will be followed by an impoved adult height. Our results demonstrate that an increase in predicted height after androgen therapy definitely does not portend an increase in adult height. In warning against over optimistic interpretation of changes in predicted height resulting from androgen therapy, Bongiovanni (4) suggested that a rapid advance in bone age might occur once therapy was discontinued, although skeletal maturation was not unduly accelerated during therapy. We were able to study the progress of skeletal maturation of eight boys, two of whom seemed to have such an acceleration, but the others did not and continued to have predicted heights greater than pretreatment predicted height for as long as they were followed.

Our results have an additional implication for the evaluation of therapies designed to affect adult height in children with severely delayed bone ages. Because $50 \%$ of such boys fail to attain at least their predicted height less $5.1 \mathrm{~cm}$, a treatment having no effect on predicted height but causing all treated children to reach their predicted height as adults would represent a significant improvement in outcome for these children. Thus, follow-up until adult height is attained is required before a therapy can be deemed effective or ineffective.

\section{REFERENCES AND NOTES}

1. Bayer L. M. and Bayley N.: Growth pattern shifts in healthy children: spontaneous and induced. J. Pediatr., 62: 631 (1963).
2. Bayley N. and Pinneau S. R.: Tables for predicting adult height from skeletal age: revised for use with the Greulich-Pyle hand standards. J. Pediatr., 40: 423 (1952).

3. Bettmann H. K., Goldman H. S., Abramowicz M., and Sobel E. H.: Oxandrolone treatment of short stature: effect on predicted mature height. J. Pediatr., 79: 1018 (1971)

4. Bongiovanni A. M.: Commentary. Anabolic drugs to promote growth. Pediatrics, 27: 519 (1961).

5. Greulich W. W. and Pyle S. I.: Radiographic atlas of skeletal development of the hand and wrist. 2nd ed., (Stanford University Press, Stanford, 1959).

6. Kaplan J. G., Moshang T. Jr., Bernstein R., Parks, J. S., and Bongiovanni, A. M.: Constitutional delay of growth and development: effects of treatment with androgens. J. Pediatr., 82: 38 (1973).

7. Reilly W. A and Gordon G. S.: Dissociation of growth-stimulating and skeleton maturing actions of the synthetic androgen, fluoxymesterone. J. Pediatr., 59: 188 (1961).

8. Rosenfeld R. G., Northcraft G. B., and Hintz R. L.: A prospective, randomized study of testosterone treatment of constitutional delay of growth and development in male adolescents. Pediatrics, 69: 681 (1982).

9. Swinscow T. D. V.: Statistics at square one. 7th ed. (British Medical Association, London, 1980).

10. Zachmann M., Sobradillo B., Frank M., Frisch H., and Prader A.: BayleyPinneau, Roche-Wainer-Thissen, and Tanner height predictions in normal children and in patients with various pathological conditions. J. Pediatr., 93: 749 (1978).

11. Presented to the Society for Pediatric Research, Washington, D.C., May 3, 1983.

12. Requests for reprints should be addressed to: Dr. S. L. Blethen, P.O. Box 14871 , St. Louis, MO, 63178.

13. This research was supported in part by grants RR-36 from the Division of Research Resources and AMO-5105 from the NIADDK of the National Institutes of Health.

14. Received for publication April 19, 1983.

15. Accepted for publication August $9,1983$.

\title{
Cold Air Challenge of Airway Hyperreactivity in Children: Practical Application and Theoretical Aspects $^{(46)}$
}

\author{
M. ZACH, ${ }^{(48)}$ G. POLGAR, ${ }^{(47)}$ H. KUMP, AND P. KROISEL \\ Department of Pediatrics, University of Graz, Graz, Austria and Children's Hospital of Michigan, Wayne State \\ University, Detroit, Michigan, USA
}

\section{Summary}

In 23 children with asthma and 18 healthy controls, cold air challenge (CACh) was done twice during the same half day, and in the asthmatics a third time together with a histamine challenge (HCh) 2 wk later. Pulmonary functions were tested before and after each challenge. No overlapping of individual responses to $\mathrm{CACh}$ in seven forced expiratory flow tests proved the power of discrimination of this technique in children. The limits of "normal" reactions ranged from minus $9 \%$ for larger airway-related to $26 \%$ for smaller airway-related flows. Short-term reproducibility of induced changes, in percentage of baseline, was excellent $(r=0.815-0.954) ;$ in percentage of predicted postchallenge abnormality it was even bettern $(r=0.926-0.975)$. The response in small airway-related flow rates $(-43.1 \pm 12.8$ to $-51.9 \pm$ $16.8 \%$ of baseline) was much larger than in others $(-27.6 \pm 14.6$ to $-32.1 \pm 17.3 \%$ of baseline). This, the different baseline-toresponse correlations in various measurements, and the divergent dose response to colder versus less cold air in large $(60.7 \pm 21.9$ versus $65.4 \pm 21.5 \%$ predicted, postchallenge values) and small airway-related tests $(28.9 \pm 18.7$ versus $29.5 \pm 15.1 \%$ predicted, postchallenge values) in asthmatic children suggest a predetermined, small airway-related limitation of individual reactivity, which is independent of the baseline situation. All asthmatics responded positively to $\mathrm{HCh}$ but quantitative results of the two methods did not correlate. Responses to CACh also better characterized the clinical severity of asthma than those to $\mathrm{HCh}$. Determining the individual optimum by a bronchodilator and the physiologic abnormality by $\mathrm{CACh}$, the whole functional dimension of a child's asthma can be established.

\section{Abbreviations}

CACh, cold air challenge

FEF $_{25-75}$, forced expiratory flow during mid-half of FVC

$\mathrm{FEV}_{1}$, forced expiratory volume in one second

FRC, functional residual capacity 